\title{
Paz y propaganda, con guerras y derrotas al fondo
}

\author{
Asunción Castro y Julián Díaz, coords. 2017. XXV Años de paz \\ franquista. Sociedad y cultura en España hacia 1964. Madrid: Sílex, \\ 443 págs.
}

\author{
FERNANDO VALLS \\ Universitat Autònoma de Barcelona (España) \\ orcid.org/0000-0001-5304-1138 \\ doi: https://doi.org/10.7238/dd.voi6.3154
}

Sorprende que hasta ahora nadie le hubiera dedicado un libro a este tema - la excepción son los fascículos de El Mundo, con buenas ilustraciones, 1964: Franco celebra sus 'XXV años de paz', publicados en el 2006 (Madrid: Unidad Editorial), aunque aquí nadie trate de la literatura, ni del arte- $\mathrm{y}$ que a ningún historiador se le hubiera ocurrido abordar en profundidad lo que significaron, desde el punto de vista social y cultural, histórico en suma, las celebraciones oficiales del régimen franquista en 1964, los denominados XXV años de paz. Sea como fuere, esta materia solo puede encararse como en este libro se hace, de manera multidisciplinar, observando los hechos desde la historia, la política, el pensamiento, el arte y la literatura, todo ello condicionado por los mecanismos propios de la propaganda.

El volumen que comentamos se divide en tres partes: la primera se ocupa del contexto, en los años sesenta; la segunda aborda el arte y la propaganda, y la tercera se centra en la literatura. Trata de cubrir los distintos campos de trabajo, aunque me temo que no siempre se consigue y unos asuntos aparecen mejor resueltos que otros, quizá porque los diversos enfoques no acaban de ser siempre los más adecuados —es el caso del estudio de Jesús Villegas Cano- ${ }^{1}$, porque se desvían hacia campos paralelos — como ocurre en el trabajo de Silvia de Álamo— o porque olvidan el prin-

1 Cuando se detiene en Señas de identidad (1965), de Juan Goytisolo, sorprende que no se comente que en dicha novela se alude a los veinticinco años de paz, ni se aclare que el personaje de Fernández remite a José María Gironella, quien no parece que titule por casualidad una de sus novelas Ha estallado la paz (1966). El estudio tiene, además, otros problemas, por lo que se refiere a la escritura (con palabros como "situacionales", "ecoico", "convencionalizado"...) o a las citas de los libros, no siempre 
cipal objeto de investigación y análisis, como sucede a veces en el campo de la literatura, en el que me centraré en la parte final de esta reseña. No digo que los dos trabajos citados carezcan de interés, pero sí parece que están metidos con calzador.

Los antecedentes inmediatos de las celebraciones fueron las campañas de 1959 y 1961, mucho más modestas, dedicadas a conmemorar los veinte años de paz y los veinticinco años del inicio de la guerra. Los protagonistas de esta gran performance de 1964, como se le llama con fortuna en la presentación del volumen, además de Franco — contaba entonces setentaiún años-, fueron el ministro de Información y Turismo, entre 1962 y 1969, Manuel Fraga Iribarne —véase, aunque la prosa sea telegráfica y resulte decepcionante, su Memoria breve de una vida pública (Barcelona: Planeta, 1980)—, y su cuñado Carlos Robles Piquer - Memoria de cuatro Españas. República, guerra, franquismo y democracia (Barcelona: Planeta, 2011) - Según cuenta este último (p. 254, las páginas remiten siempre al libro reseñado), la conmemoración costó unos 75 millones de pesetas y para su organización se creó la Junta Interministerial y tres comisiones. Una la presidió él mismo, y las otras dos, José María Hernández Sampelayo, la de Publicaciones, y José María López de Valencia, la de Actos públicos. El lema principal de la campaña, cuyos actos oficiales empezaron el 1 de abril, era «Paz», y el eslogan, «XXV Años de paz».

El objetivo estribaba en que los conceptos de paz y prosperidad sustituyeran a los de cruzada y victoria en la retórica propagandística del régimen, hasta el punto de que el denominado Desfile de la Victoria pasó a llamarse Desfile de la Paz. No en vano, los dirigentes del régimen empezaron a darse cuenta de que su meta económica tendría que ser Europa, pero si querían integrarse en la Comunidad Europea necesitaban articular nuevos discursos que pudieran legitimar ante las democracias europeas, sustituyendo la caduca retórica falangista por otra más pragmática y tecnocrática. Se trataba, en suma, de venderle una ética burocráticoempresarial a una sociedad católica, mediante la santificación del trabajo (págs. 131-133).

correctas y a veces incompletas, como ocurre en la nota 17, lo que hace pensar que no los ha visto, pero no es este el lugar adecuado para insistir en ello. 
Aunque la razón de las celebraciones provenía de las necesidades del propio desarrollo de la política nacional, tengo la impresión de que en el fondo también había una cierta respuesta a los congresos comunistas por la paz, como el Congreso Mundial de Intelectuales en Defensa de la Paz, celebrado en Wroclaw (1948), ${ }^{2}$ así como los sucesivos en Nueva York (1949), París (1949), Estocolmo (1950), Varsovia (1950) y Viena (1952). Recuérdese, además, que la encíclica de Juan XXIII, Pacem in terris, data de 1963 y — valga como único ejemplo- que el artista exiliado republicano español José Vela Zanetti realizó un mural en la sede de la ONU, en Nueva York, que llevaba por título La ruta de la libertad o La lucha del hombre por la paz (1953). Esta obra fue un regalo de la República Dominicana —la del dictador Trujillo - al organismo internacional, en el contexto de la Guerra Fría, conforme a la disputa entre los países occidentales y los regímenes comunistas por apropiarse, haciéndola suya, de la idea de la paz. En el contexto de esas conmemoraciones, el PCE las celebró en México en los primeros años cincuenta, que fue cuando apareció en dicho país la revista dirigida por León Felipe España y la Paz (1951-1955).

Alrededor de 1964 —entre 1956 y 1966 — podría decirse que se produce en España una aceleración de la historia, tanto por los acontecimientos europeos como por el propio desarrollo interno de la sociedad española. En la primera fecha, el PCE decide apostar por una política de reconciliación nacional; y en la última se proclama la Ley Orgánica del Estado y la de Prensa o Ley Fraga. Pero, además, el cambio de gobierno de 1957 supone la llegada al poder de los tecnócratas del Opus Dei. El año siguiente comienza el pontificado de Juan XXIII, a quien se deben dos importantes encíclicas: Mater et Magistra (1961) y la ya citada. Por su parte, 1959 trajo consigo el Plan de Estabilización, que transformaría la economía española, y el simbólico abrazo de Franco y Eisenhower. En 1962 Manuel Fraga Iribarne es nombrado ministro de Información y Turismo, cargo en el que permanecerá hasta 1969. En esa fecha los salarios superan, por primera vez después de la guerra, el nivel que tenían en 1935. Se produce el primer

2 Véase Max Aub, «Congreso Mundial de los Intelectuales», Últimas Noticias [México], 17 jul. 1948. Recogido en Eugenia Meyer, ed., Los tiempos mexicanos de Max Aub. Legado periodístico 1943-1972 (Madrid: F.C.E., 2007), 372. 
intento de adhesión de España, sin éxito, al Mercado Común Europeo; la llegada de un nuevo gobierno; la huelga de mineros en Asturias; la reunión de Munich, y el comienzo de la emigración masiva de los trabajadores españoles a Europa. Julián Grimau es ejecutado en 1963. Durante el año siguiente se crea el Tribunal de Orden Público; se inauguran los nuevos estudios de TVE en Prado del Rey; España se proclama campeona de Europa de selecciones nacionales de fútbol frente a la URSS, con el famoso gol de Marcelino que ya forma parte de la mitología deportiva nacional, y Guinea Ecuatorial se convierte en territorio autónomo, consiguiendo la independencia en 1968. Por último, en 1965 se clausura el Concilio Vaticano II y se disuelve el SEU.

Son también los años del estreno de la película El pisito (1959), de Marco Ferreri; de la novela La mina (1960), de Armando López Salinas, activo militante del partido comunista; del inicio de la nueva época de la revista Triunfo (1962); de la exposición en Madrid dedicada al Arte de América y España (1963), en la que Tàpies, Antonio Saura y Manolo Millares decidieron no participar, y cuando sale a la luz la revista Cuadernos para el Diálogo (1963) y reaparece la Revista de Occidente. Asimismo, por entonces, se inaugura la exposición España en paz, con el célebre cartel de Julián Santamaría anunciando la celebración (1964); ${ }^{3}$ se estrena la película encargada a José Luis Sáenz de Heredia Franco. Ese hombre (1964), de la que fue coguionista José María Sánchez Silva, el autor de Marcelino, pan y vino; el 12 de octubre de 1964 se inaugura la exposición XXVAños de arte español, cuyo catálogo estuvo al cuidado de José Camón Aznar, y el 16 de junio del mismo año el Orfeón Donostiarra da el Concierto de la Paz. Asimismo, el obispo de Canarias, monseñor Pildain, publica El turismo y las playas, las divisas y otros escándalos (1964). Pero también es cuando ve la luz el Manifiesto sobre arte y libertad. Encuesta entre los intelectuales y artistas españoles (1964), de Sergio Vilar; se publica El crepúsculo de las ideologías (1965), de Gonzalo Fernández de la Mora; aparece la editorial Ciencia Nueva, vinculada al PCE (1965); los Beatles actúan por primera

3 Según Ramón Vicente Díaz del Campo, la función de los carteles consistía en «transmitir la idea de que el gobierno franquista se preocupaba del bienestar social de los ciudadanos» (p. 221). También fueron autores de carteles semejantes Tono, Herreros, Mena, Mingote... 
vez en España en julio de 1965; se inicia la colección «El Libro de Bolsillo», de Alianza Editorial (1966), y se inaugura el Museo de Arte Abstracto de Cuenca (1966). En suma, un sinfín de actos, acontecimientos y celebraciones que dan cumplida cuenta de esa aceleración de la historia mencionada.

Entre las publicaciones más significativas está la colección «España en Paz», formada por un conjunto de libros dedicados a cada una de las provincias españolas. Presentan una moderna y sobria maqueta común y un formato cuadrado de tamaño reducido, con dieciséis fotos en blanco y negro, bien estudiada en este volumen, aunque se ciña sobre todo a los dedicados a las provincias de Castilla-La Mancha. Una vez más, habría que destacar a algunos de sus autores: Pedro de Lorenzo, Lorenzo Villalonga (firmaba en castellano), José María Gironella, Victoriano Crémer, Álvaro Cunqueiro, José Luis Castillo-Puche, Antonio Gala, José María de Cossío, José García Nieto, Antonio Prieto, José María Pemán...

Por lo que se refiere a la literatura, más que el contexto en que se produjo la celebración, que también hay que considerar, interesan los libros que aparecieron, estrechamente vinculados, como encargo y resultado de las celebraciones, entre otras razones porque su entidad literaria resultó modesta, pero nos proporciona una nómina de los periodistas y escritores afines al régimen, o al menos de cuantos no le hacían ascos, ni les importaba significarse y querían agradar. Así, podría citarse el volumen colectivo titulado Panorama español contemporáneo. XXV Años de paz (Madrid: Cultura Hispánica, 1964), en el que tienen especial interés para nuestro propósito los capítulos dedicados al ensayo y al pensamiento (Gonzalo Fernández de la Mora); la novela, en la que su autor, José Luis Castillo Puche, no tiene empacho alguno en dedicar una parte no precisamente breve a hablar de su propia obra, sin que en ningún otro lugar se ocupe nadie del resto de los géneros literarios; y a la labor del Instituto de Cultura Hispánica (Enrique Suárez de Puga). De semejantes hechuras es El libro 25 años de paz vistos por 25 escritores (Madrid: Servicio Informativo Español, 1964), entre los que se encontraban: el periodista Lucio del Álamo; el poeta y articulista Manuel Alcántara; el cubano afincado en España, y gran poeta, Gastón Baquero; Juan Bonet, el padre de la cantante Maria del Mar Bonet; el crítico de arte José Camón Aznar; los escritores y periodistas Rafael García Serrano, Pedro de Lorenzo y Adolfo Muñoz Alonso; 
los periodistas de radio o televisión Basilio Gassent y José Luis Pécker; el político falangista Jesús Suevos, y el escritor monárquico José María Pemán, entre otros muchos creo que menos notables.

Pero quizás el libro estrella fuera, por lo que respecta a lo literario, por su formato y lo cuidado de su edición, ilustrada, la antología Un cuento de guerra y 25 historias de paz (Madrid: Jefatura Central de Tráfico del Ministerio de la Gobernación, 1964), en el que colaboran, entre otros: Rafael García Serrano, Carlos Luis Álvarez (Cándido), Miguel Buñuel, José Luis Coll, Medardo Fraile, José García Nieto, Ángela C. Ionesco, María Elvira Lacaci, Concha Lagos, Rafael Morales, Federico Muelas, Manuel Pilares, Manuel Pombo Angulo, Julio Trenas, Mariano Tudela, Francisco Umbral y José María Sánchez Silva. Por el contrario, resulta sorprendente que no se publicara una antología semejante de poesía, aunque Gil de Biedma —en la estela de Larra - se ocupara de los festejos y de la situación del país y de sus escritores en «Carta de España (o todo era Nochevieja en nuestra literatura al comenzar 1965)", publicado en The Nation el 1 de marzo de 1965. Sí se celebraron, en cambio, unas Justas poéticas de la paz (p. 115), cuyo ganador fue Manuel Alcántara con su poema «Carta a un poeta que murió fuera de España», en referencia a Antonio Machado. Para el autor, la paz que gozaban los españoles era producto de aquella guerra, y gracias a ella. ${ }^{4}$

Habría que estudiar — creo que no se ha hecho- las reacciones que suscitaron y las repercusiones que tuvieron estas celebraciones en el ámbito de la cultura catalana — el abad de Montserrat las denominó «25 años de Victoria» y el centro de TVE en Barcelona emitió, el 27 de octubre de 1964, el primer programa en catalán, una adaptación de La ferida lluminosa, de Josep Maria de Sagarra-, gallega y vasca; también entre los componentes del exilio republicano español, a quienes se alude en este libro en numerosas ocasiones, para recordar — por ejemplo— que las celebraciones de 1964 permitieron una cierta relajación de la censura con las obras de Ramón J. Sender o Alejandro Casona, quien en esa fecha presenta en Madrid El caballero de las espuelas de oro, su primera obra llevada a escena tras regresar a España. Pero también se estrenó Ninette y un señor de Murcia,

4 El poema se publicó en $A B C$, el 4 de agosto de 1972, pero que yo sepa no está recogido en ninguno de los libros de Manuel Alcántara. 
de Mihura, obra con la que obtuvo el Premio Calderón de la Barca, donde ridiculiza a una familia de exiliados en París (págs. 357, 374 y 380). Por su parte, Max Aub se refiere en diversas ocasiones a lo largo de su obra a lo que denomina —en una carta a Tuñón de Lara de 1964 — «la celebración (?) de los 25 años de nuestra derrota». Fernando Larraz ha llamado la atención sobre ese giro pragmático, que se explicita en una carta de Robles Piquer a Fraga, en la que le comenta que es preferible que las obras se publiquen en España con algunos cortes, en vez de prohibirlas, y que aparezcan completas en el extranjero, con el consiguiente escándalo que ello podría suponer. ${ }^{5}$

El libro, en suma, puede leerse como una historia de la vida política y cultural española en los sesenta, y como concluye Antonio Cazorla Sánchez en el clarificador artículo inicial: «la campaña de los XXV Años de Paz fue el espejo deformado, manipulado por el franquismo, de la realidad de la España de 1964» (p. 45), en sus diversos ámbitos, ya sea histórico, político o cultural. 